\title{
Modelling and Assessment of Accidental Gas Release from Damaged Subsea Pipelines
}

\author{
Ahmed M. Ellethy, Ahmed S. Shehata, Ali I. Shehata, and Ahmed Mehanna
}

\begin{abstract}
Due to the high demand on hydrocarbon exploration nowadays and in future overall the world, the risk potential of Subsea gas and oil leakage increases and can lead to a catastrophic incidents such as explosion, fire or loss stability of subsea constructions. Therefore, the purpose of this paper is to assess and control the potential of hazards for the gas flows from subsea pipelines rupture to sea surface with varying of influence parameters on gas plume. 2D Computational Fluid Dynamics (CFD) simulations have been carried out. The influence parameters that contained in the present paper leakage hole sizes and water depths. The Rotvoll experiment data is used in order to validate numerical computational fluid dynamics model. The subsea gas diffusion behavior is investigated for the risk assessment aspect. The main parameters which included to assess the gas dispersion are rising time and fountain height. Observed from our sceneries results that the water depth has a major effect on gas rise time where the deeper water depth is about 3 times longer than the lower water depth to reach water surface whilst the hole size has a high effect on the fountain height where the larges hole size is approximately 2.1 times higher than the smaller hole size. So our objective is helping the petroleum companies to find a mitigation method by modelling and assessing the gas release in order to contain the subsea gas leakage.
\end{abstract}

Index Terms-Underwater gas leakage, risk assessment, gas dispersion, hole size, water depth.

\section{INTRODUCTION}

After centuries of technology the exploration and extraction of hydrocarbon resources have expanded offshore and into deeper waters, the Gulf of Mexico is one of the most important regions for energy resources and infrastructure for both onshore and offshore. Gulf of Mexico's offshore oil production reached to $17 \%$ of total U.S. oil production. Offshore gas production in the Gulf contributed for $5 \%$ of U.S. dry production in total. Over than $45 \%$ of U.S. oil refining capacity was placed along the Gulf Coast [1]. As seen in Fig. 1. Therefore, the risk of potential leakage is also rising at the same time with the number of subsea structure installations and pipelines increases. Subsea extraction and transport techniques have been developed, including the subsea pipeline, Pipelines are widely used to transport the hydrocarbon fluids and fossil fuels and chemicals over millions of miles across the world.

The pipeline structures are designed to Steadfastness

Manuscript received December 30, 2020; revised March 10, 2021.

Ahmed M. Ellethy and Ali I. Shehata are with the Department of Mechanical, College of Engineering and Technology, Arab Academy for Science, Technology and Maritime Transport, Alexandria, Egypt (e-mail: ahmedellaithy1992@gmail.com).

Ahmed S. Shehata and Ahmed Mehanna are with the Department of Marine, College of Engineering and Technology, Arab Academy for Science, Technology and Maritime Transport, Alexandria, Egypt. against several severe environmental conditions in order to maintain an environment and reliable distribution along the pipeline production from the production wells to shore. And pipeline considers one of the most important assets for petroleum companies. Likewise, the more professional approach by developing the Risk assessment plans for any offshore structures installations, including the predicting impact consequence of a variety of catastrophic events. This could involve the leakage from any hydrocarbon containment from topsides or subsea equipment such as subsea pipelines, risers, production $\mathrm{x}$-tree and production manifold [2].

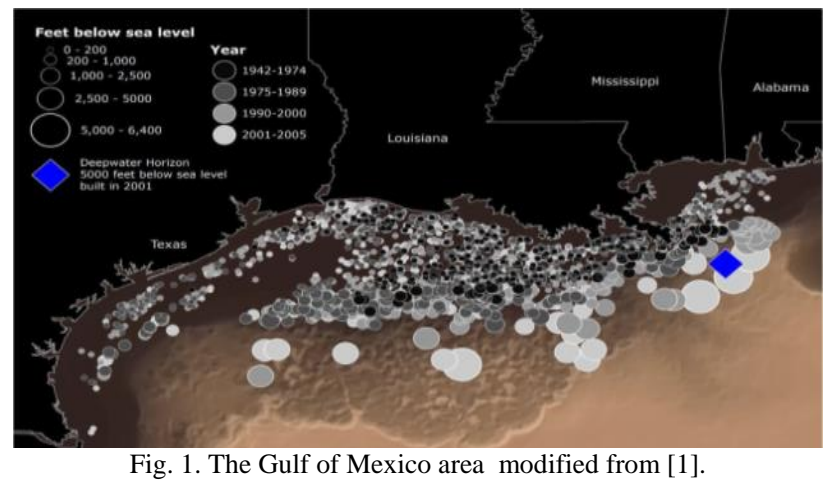

The sub-sea pipeline release relies on if the leakage fluids are in liquid or gaseous form. If the leakage is in the liquid phase, the buoyancy will contribute in the diffusion of the liquid due to the liquid release is lighter than the water on the surface of the water. This diffusion will lead to pollution spot, or it will lead to a pool of fire. In the case of the ignition source is exist, Even though the gas buoyancy is more larger than for liquids leakage, drag forces will allow the plume to split up between the leakage point and the water surface, and the released gas will rise to the surface as a stream of gas bubbles [3].

Many researchers have implemented a number of studies on the leakage of underwater gas in the last decades and have made a significant contribution. Many factors have been shown to have impacts on underwater plume behavior, such as sea currents, gas dissolution, hydrate creation and hydrate decomposition by [4].

Li. et al. [5] Studied the systematic simulation and evaluation of subsea release gas deflagration and diffusion using an Integrated CFD model to analyze the development of the incident scenario and The jack-up drilling rig is used as a case in point to identify the effects of gas deflagration and diffusion on surface platform. Xu. et al. [6] investigated a systematic simulation and assessment of gas dispersion above sea from a Subsea gas release by developing a 3D CFD model to evaluate the behavior patterns of flammable gas above sea level, and the jack-up drilling rig is used to demonstrate the effect of the cloud of gas on surface. The 
author has observed that the size of the hazardous area decreases with an increase in the release rate of the surface gas. Also Li. et al. [7] presented an experimental and numerical analysis of the release and dispersion behavior of subsea gas. A variety of release scenarios are conducted to study the impact of release pressure, water depth and leak direction on dispersion behavior. The author observed that the gas plume under the larger leak pressure has been shown to have a higher volume. The effect of the leaking pressure on the gas plume is also equivalent to the size of the nozzle. An experimental has been designed in order to test gas leakage rate and dispersion behavior in various scenarios with considering orifice size, leakage pressure and water depth effect on gas flow rate a by using a transparent glass container with a dimension of $1 \mathrm{~m} \times 0.5 \mathrm{~m} \times 0.5 \mathrm{~m}$ was located inside wind tunnel. The author [8] observed that the gas release rate increased approximately linearly with an increasing in pressure at $0.75 \mathrm{~m}$. Gathered some information about the previous studies as can be summarized in Table I.

Therefore, the purpose of this study is to investigate the behavior of gas release and dispersion characteristics and also to determine subsea rise time, gas transport path and fountain height until reach sea surface with using production gas density of Petroleum Egyptian company around $0.648 \mathrm{~kg}$ $/ \mathrm{m}^{3}$ and study the effects of the hole size and water depth on subsea gas release by developing a CFD model in order to find mitigation method to contain the subsea gas release.

TABLE I: INFORMATION ABOUT THE PREVIOUS STUDIES

\begin{tabular}{|c|c|c|c|c|c|c|c|c|c|}
\hline Authors & $\begin{array}{l}\text { Numerical } \\
\text { models }\end{array}$ & $\begin{array}{c}\text { Turbulenc } \\
\text { e model }\end{array}$ & Hole size & $\begin{array}{l}\text { Water } \\
\text { depth }\end{array}$ & $\begin{array}{c}\text { Validation } \\
\text { model }\end{array}$ & $\begin{array}{c}\text { Pressure } \\
\text { discretizati } \\
\text { on }\end{array}$ & $\begin{array}{l}\text { Continuity, } \\
\text { momentum } \\
\text { and } \\
\text { turbulence } \\
\text { equations }\end{array}$ & $\begin{array}{c}\text { Pressure } \\
\text { velocity } \\
\text { coupling, }\end{array}$ & $\begin{array}{l}\text { Volume } \\
\text { fraction }\end{array}$ \\
\hline [9] & $\begin{array}{l}\text { Coupled } \\
\text { VOF and } \\
\text { DPM } \\
\text { approach }\end{array}$ & $\begin{array}{c}\text { The } \\
\text { standard K- } \\
\varepsilon \\
\text { model }\end{array}$ & - & $\begin{array}{c}30 \mathrm{~m}, 100 \\
\mathrm{~m} \text { and } 400 \\
\mathrm{~m}\end{array}$ & $\begin{array}{c}\text { Rotvoll } \\
\text { experiment }\end{array}$ & PRESTO! & $\begin{array}{l}\text { Second } \\
\text { order } \\
\text { upwind } \\
\text { scheme }\end{array}$ & $\begin{array}{c}\text { PISO } \\
\text { scheme }\end{array}$ & $\begin{array}{c}\text { The } \\
\text { Geo-Recon } \\
\text { struct } \\
\text { algorithm }\end{array}$ \\
\hline [10] & $\begin{array}{l}\text { Coupled } \\
\text { VOF and } \\
\text { DPM } \\
\text { approach }\end{array}$ & $\begin{array}{c}\text { The } \\
\text { realizable } \\
\kappa-\varepsilon \\
\text { turbulence } \\
\text { model }\end{array}$ & $\begin{array}{c}10 \mathrm{~mm}, 50 \\
\mathrm{~mm}, 100 \\
\mathrm{~mm}, \text { and } \\
\text { full rupture. }\end{array}$ & $\begin{array}{c}\text { Several } \\
\text { depth } \\
\text { approximat } \\
\text { ely from } 50 \\
\text { m to } 235 \mathrm{~m}\end{array}$ & $\begin{array}{c}\text { Rotvoll } \\
\text { experiment }\end{array}$ & PRESTO! & $\begin{array}{l}\text { Second } \\
\text { order } \\
\text { upwind } \\
\text { scheme }\end{array}$ & $\begin{array}{c}\text { PISO } \\
\text { scheme }\end{array}$ & $\begin{array}{c}\text { The } \\
\text { Geo-Recon } \\
\text { struct } \\
\text { algorithm }\end{array}$ \\
\hline [11] & $\begin{array}{l}\text { Coupled } \\
\text { VOF and } \\
\text { DPM } \\
\text { approach }\end{array}$ & $\begin{array}{c}\text { The } \\
\text { realizable } \\
\kappa-\varepsilon \\
\text { turbulence } \\
\text { model }\end{array}$ & $30 \mathrm{~mm}$ & $\begin{array}{c}30 \mathrm{~m}, 50 \mathrm{~m}, \\
\text { and } 70 \mathrm{~m}\end{array}$ & $\begin{array}{c}\text { Rotvoll } \\
\text { experiment }\end{array}$ & PRESTO! & $\begin{array}{l}\text { Second } \\
\text { order } \\
\text { upwind } \\
\text { scheme }\end{array}$ & $\begin{array}{c}\text { PISO } \\
\text { scheme }\end{array}$ & $\begin{array}{c}\text { The } \\
\text { Geo-Recon } \\
\text { struct } \\
\text { algorithm }\end{array}$ \\
\hline [12] & $\begin{array}{l}\text { Coupled } \\
\text { VOF and } \\
\text { DPM } \\
\text { approach }\end{array}$ & $\begin{array}{c}\text { The } \\
\text { standard K- } \\
\varepsilon \\
\text { model }\end{array}$ & $25.4 \mathrm{~mm}$ & $\begin{array}{c}50 \mathrm{~m} \text { and } \\
300 \mathrm{~m}\end{array}$ & $\begin{array}{c}\text { Rotvoll } \\
\text { experiment }\end{array}$ & PRESTO! & $\begin{array}{l}\text { Second } \\
\text { order } \\
\text { upwind } \\
\text { scheme }\end{array}$ & $\begin{array}{c}\text { PISO } \\
\text { scheme }\end{array}$ & $\begin{array}{c}\text { The } \\
\text { Geo-Recon } \\
\text { struct } \\
\text { algorithm }\end{array}$ \\
\hline [13] & $\begin{array}{l}\text { Coupled } \\
\text { VOF and } \\
\text { DPM } \\
\text { approach }\end{array}$ & $\begin{array}{c}\text { The } \\
\text { standard K- } \\
\varepsilon \\
\text { model }\end{array}$ & - & $7 \mathrm{~m}$ & $\begin{array}{c}\text { Rotvoll } \\
\text { experiment }\end{array}$ & PRESTO! & $\begin{array}{l}\text { Second } \\
\text { order } \\
\text { upwind } \\
\text { scheme }\end{array}$ & $\begin{array}{c}\text { PISO } \\
\text { scheme }\end{array}$ & $\begin{array}{c}\text { The } \\
\text { Geo-Recon } \\
\text { struct } \\
\text { algorithm }\end{array}$ \\
\hline
\end{tabular}

\section{Methodology}

\section{A. Modeling Approach of Underwater Gas Release}

The Eulerian-Lagrangian modelling approach is a hybrid two-way coupling modeling approach consisting of the Eulerian-Lagrangian Discrete Phase Model (DPM) and the Eulerian-Eulerian Volume of Fluid Model (VOF) also the common name is coupled DPM and VOF model. In this paper the discrete particles is referred to the bubble and the continuous phase is referred to the water (The fluid in the computational domain). DPM tracks the movement of discrete particles, whilst VOF describes the movement of the continuous phase. The volume ratio is measuring parameter for the distribution of different phases. In the computational domain, the Eulerian volume of fluid model considers the volume occupied by the released gas and the summing volume of the water and the released gas equal one.

\section{B. Theoretical Model}

\section{1) The Eulerian-Eulerian volume of Fluid Model (VOF)}

$\mathrm{VOF}$ is a strategy of free surface tracking under the constant Eulerian mesh. The interacting mediums are all different phases in the computational domain and the volume of one phase cannot be occupied by other phases. The governing equations show the interact between discrete particles move through continuous phase by exchanging mass conservation, momentum conservation, and energy conservation [12].

The mass conservation equation is shown as in (1), where $\alpha_{q}$ is volume fraction of $q_{t h}$ phase, $\rho_{q}$ is the density of $q_{t h}$ phase and where $\vec{v}_{q}$ is the velocity of $\mathrm{q}_{\text {th }}$ phase.

$$
\frac{\partial}{\partial \mathrm{t}}\left(\alpha_{q} \rho_{q}\right)+\nabla \cdot\left(\alpha_{q} \rho_{q} \vec{v}_{q}\right)=0
$$

The momentum equation is shown as in (2), where $\vec{v}_{q}$ is the velocity of $\mathrm{q}_{\mathrm{th}}$ phase, $\rho$ is the density of mixed phases, which is getting from (3). $\rho$ and $\vec{F}$ are the gravitational body force and external body force, $\mu$ is viscosity that is the sum of molecular mixture viscosity and turbulent viscosity. So the characteristics $\rho$ and $\mu$ are the most important as the momentum equation rely on volume fractions of phases.

$$
\frac{\partial}{\partial \mathrm{t}}(\rho \vec{v})+\nabla \cdot(\rho \vec{v} \vec{v})=-\nabla \mathrm{p}+\nabla \cdot\left[\mu\left(\nabla \vec{v}+\nabla \vec{v}^{T}\right)\right]+\rho \vec{g}+\vec{F}
$$




$$
P=\sum \alpha_{q} \rho_{q}
$$

The energy equation is shown as in (4), where keff is the effective thermal conductivity coefficient; $S h$ is the source term which is equal 0 by default.

$$
\frac{\partial}{\partial \mathrm{t}}(\rho E)+\nabla \cdot(\vec{v}(\rho E+p))=\nabla \cdot\left(k_{e f f} \nabla T\right)+S h
$$

The standard k-epsilon model is the model of turbulence. In order to represent the turbulent properties of the flow, the standard $k$-epsilon model is comprised of two extra transport equations. Turbulent kinetic energy is the first transport parameter, $K$, the second transport parameter is turbulent dissipation, $\varepsilon$, the two equations are shown below in (5) \& (6).

$$
\begin{gathered}
\frac{\partial(\rho \mathrm{K})}{\partial \mathrm{t}}+\operatorname{div}(\rho \mathrm{K} \overrightarrow{\mathrm{u}})=\operatorname{div}\left(\frac{\mu_{\mathrm{t}}}{\sigma_{\mathrm{k}}} \operatorname{grad} \mathrm{K}\right)+2 \mu_{\mathrm{t}} \mathrm{S}_{\mathrm{ij}} \cdot \mathrm{S}_{\mathrm{ij}}-\rho \varepsilon \\
\frac{\partial(\rho \varepsilon)}{\partial \mathrm{t}}+\operatorname{div}(\rho \varepsilon \overrightarrow{\mathrm{u}})=\operatorname{div}\left(\frac{\mu_{\mathrm{t}}}{\sigma_{\varepsilon}} \operatorname{grad} \varepsilon\right)+\mathrm{C}_{1 \varepsilon} \frac{\varepsilon}{\mathrm{K}} 2 \mu_{\mathrm{t}} \mathrm{S}_{\mathrm{ij}} \cdot \mathrm{S}_{\mathrm{ij}}- \\
\mathrm{C}_{2 \varepsilon} \rho \frac{\varepsilon^{2}}{\mathrm{~K}}
\end{gathered}
$$

where $\sigma_{k}=1.00, \sigma_{\varepsilon}=1.30, C_{2 \varepsilon}=1.92, C_{1 \varepsilon}=1.44$. and The flow was believed to be fully turbulent, and the molecular viscosity influences were negligible. Therefore, the standard $\mathrm{k}-\varepsilon$ model is valid for completely turbulent flows only. This model's drawback is delayed and separation decreased.

\section{2) Eulerian-Lagrangian discrete phase model (DPM)}

DPM tracks the movement of discrete particles (bubbles) in the water from the released gas. The trajectory of the bubbles is solved by the particle force equation in the differential Lagrangian coordinate frame. In Cartesian coordinates frame, the force balance equation of particles is shown in (7). Bubble inertia is proportional to the different forces that act with bubbles, additional to drag force, buoyancy and mass force [14].

$$
\frac{\mathrm{du}_{b}}{\mathrm{dt}}=\frac{\mathrm{g}\left(\rho_{b}-\rho\right.}{\rho_{b}}+F_{D}+F_{V M}
$$

The subsea gas plume motion is affected by the changing in Temperature and Hydrostatic Pressure Losses. Temperature and hydrostatic pressure are the main factors for bubble properties such as size and density, the ideal gas law usually defines them. The movement of bubbles is combined with the continuous phase flow. To measure the flow of the continuous phase, an Eulerian VOF model preserving momentum and mass via the Navier-Stokes equations. The continuous phase mass transformation is represented by the continuity equation, which is a simplified form considering the flow is diluted and the impact of the bubbles can be ignored [15].

where $u_{b}$ is the velocity of the bubbles, $\rho_{b}$ is the density of the bubbles gas, $u$ is the velocity of the fluid, $\rho$ is the density of continuous phases, $F_{D}$ is drag force, $N ; F_{V M}$ is virtual mass force and determine the drag force from (8).

$$
F_{D}=\frac{18}{\rho_{\mathrm{b}} d^{2} b} \frac{C_{D} R e}{24}\left(u_{b}-u\right)
$$

where $C_{D}$ is the drag coefficient, $\rho_{b}$ is the density of the bubble gas, $\operatorname{Re}$ is the Reynolds number and $\left(u_{b}-u\right)$ is a velocity difference between bubble velocity and liquid velocity, also the turbulent dispersion is generated by the turbulent velocity variation of the drag force. To evaluate the turbulent dispersion of gas bubbles, the Eulerian-Lagrangian model utilize a random tracking model so the turbulent velocity variance is calculated by (9).

$$
u^{\prime}=\xi \sqrt{K}
$$

where $\xi$ is a random number subject to Gaussian distribution; $K$ is turbulent kinetic energy.

In the $K-\varepsilon$ model, the determined time of bubble particles moving in turbulent vortices as in (10).

$$
t_{e}=0.15 \frac{K}{\varepsilon}
$$

where $t_{e}$ is an existence period of turbulent vortices and $\varepsilon$ turbulent energy dissipation rate.

\section{Model Descriptions}

\section{1) Geometry and mesh model}

The two dimensional geometry built in ANSYS design modeler the same dimensions as the experimental basin, with width of $9 \mathrm{~m}$ and depth of $7 \mathrm{~m}$ plus $3 \mathrm{~m}$ for air above the water surface. A uniform grid size is created in ANSYS Meshing then the mesh has been refined by region adapting in ANSYS Fluent, around the gas plume area is refined as shown in Fig. 2. (a) and (b). Increased number of cells till reached to the optimum grid cells that didn't make more changes in simulation results, therefore, the simulations have performed with 96899 quadrilateral cells also used time step size at 0.001 to get better results and keep courant number below 1 .

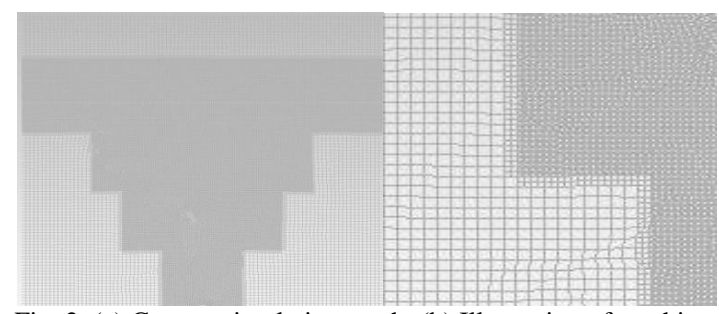

Fig. 2. (a) Current simulation mesh; (b) Illustration of meshing.

\section{2) Solution method}

An unsteady solver based on pressure is used. For unsteady simulations, the PISO algorithm is sufficient and is used for pressure and velocity coupling [14]. In order to enhance model stability in the gravity field, the implicit body force formulation is enabled. For interface tracking of various phases, the Geometric-Reconstruct scheme is used. Stochastic monitoring (random walk) considers the additional drag force of the dispersion phase (gas bubbles) in the turbulent dispersion [9]. First order implicit for transient formulation and second order upwind for turbulent kinetic energy, momentum and turbulent dissipation rate. The numerical model is implemented by the fluent software with a set of UDFs. The viscosity and density of the water phase are set to $1.003 \mathrm{e}-3 \mathrm{~kg} / \mathrm{m} . \mathrm{s}$ and $998.23 \mathrm{~kg} / \mathrm{m}^{3}$ respectively. For air, it was given as $1.7894 \mathrm{e}-5 \mathrm{~kg} / \mathrm{m} . \mathrm{s}$ and $1.225 \mathrm{~kg} / \mathrm{m}^{3}$.

\section{3) Model validation}

A numerical model is generated with the same size as The experiment is called "Rotvoll" and summarized in the report 
of [16] to check the validity of the numerical model. A series of experiments were carried out in a rectangular basin with a depth of $7 \mathrm{~m}$ and $9 \mathrm{~m}$ width. The pipeline was linked at the release point between this vessel and the bottom centre of the basin. To hold the downstream pressure constant at a preset value to achieve a constant flow rate during release, a pressure regulator was installed in the pipeline. The underwater gas plume characteristics were captured by a high-speed video camera. The basin was filled with water and pure air released from the bottom with flow rate of 83,170 and $750 \mathrm{Nl} / \mathrm{s}$. The inlet consisted of a release valve with a fast acting piston that injects gas vertically with a 10 streams of particles are arranged at $0.33 \mathrm{~m}$ in front of the release point.

\section{RESUlTS AND DisCUSSION}

\section{A. Validation Results}

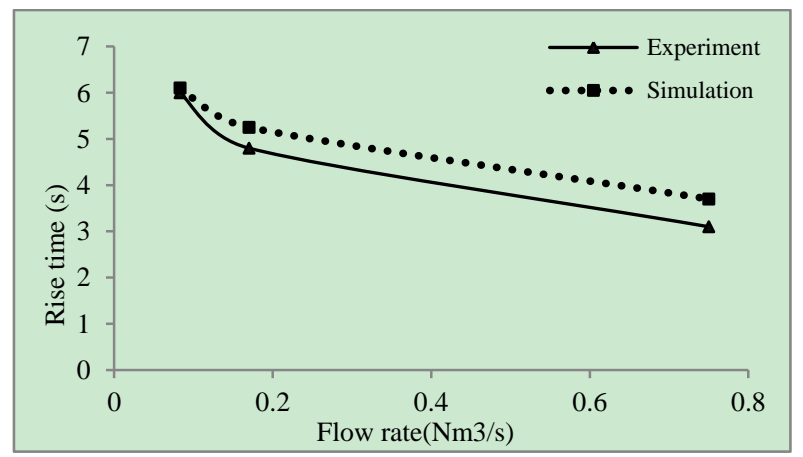

Fig. 3. Rise time comparision for gas volume flow rates of $0.085 \mathrm{Nm} 3 / \mathrm{s}, 0.17$ $\mathrm{Nm}^{3} / \mathrm{s}$ and $0.75 \mathrm{Nm}^{3} / \mathrm{s}$ between experiment and simulation.

In order to compare experimental and simulation findings, the rise time, centerline velocity and fountain height are chosen as reference parameters. There is some lack of experimental data for flow rate $0.75 \mathrm{Nm}^{3} / \mathrm{s}$. The simulation and experimental rise time are concise in Fig. 3. The rise time defines with the first particle reach the water surface. The simulation and experimental fountain height are summarized in table II and finally the Centre line velocity is summarized in Fig. 4. (a) and (b). For comparing experimental and simulation outcomes. The rise time and fountain height are selected as reference variables the same as [11]. Found that the outcomes of the simulation are magnificently aligned with the experiments, It can be shown that the simulated values are greater than the experimental values induced by the $\mathrm{k}-\varepsilon$ model, which only provides the average turbulence knowledge and lacks the ability to dissipate the elevated momentum around the gas core to water. The URANS LES turbulence model has been shown to display a more reliable estimate of plume centerline velocity than the RANS k- $\varepsilon$ model. Furthermore, a disadvantage of overlong measurement time, which cannot be neglected. The current numerical model is still used for further discussion because the prediction error with the current turbulence model is inside a reasonable range and also the affordable time cost. The contour plot of volume fractions in Fig. 5 shows the deflected rising water upward in radial surface flow occurs due to the momentum of the entrained water plume, this elevation is clear evidence of the two-way coupling used in the present CFD simulation. The blue color represents the phase of the water (continuous phase) and the ambient air is represented by the red color. The yellow line reflects the interface between the two phases that illustrated by the Geo Reconstruction Scheme. Fig. 6 shows the bubble contour for particle residance time after 5 seconds at flow rate 0.17 $\mathrm{Nm}^{3} / \mathrm{s}$.

TABLE II: FOUNTAIN HEIGHT COMPARISON FOR GAS VOLUME FLOW RATES OF $0.17 \mathrm{~N} / \mathrm{S}$ AND $0.75 \mathrm{~N} / \mathrm{S}$ BETWEEN EXPERIMENT AND SIMULATION

\begin{tabular}{|l|l|l|l|}
\hline & \multicolumn{3}{|l|}{ Fountain height $(\mathrm{m})$} \\
\hline Flow rate $\left(\mathrm{Nm}^{3} / \mathrm{s}\right)$ & 0.083 & 0.17 & 0.75 \\
\hline Experiment & - & 0.65 & 1.28 \\
\hline Simulation & 0.25 & 0.56 & 1.21 \\
\hline
\end{tabular}

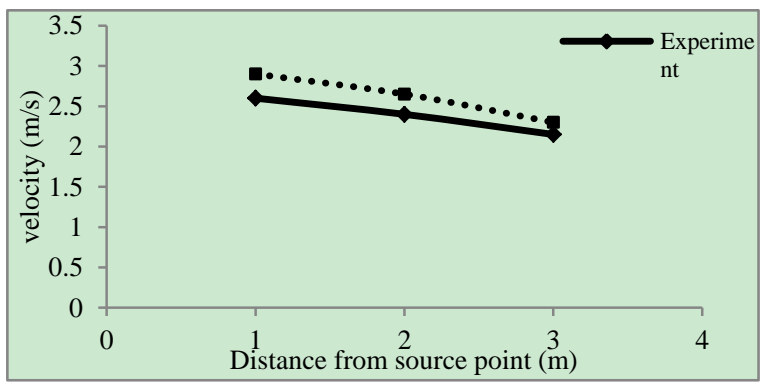

(a) Gas volume flow rate $0.085 \mathrm{Nm} 3 / \mathrm{s}$

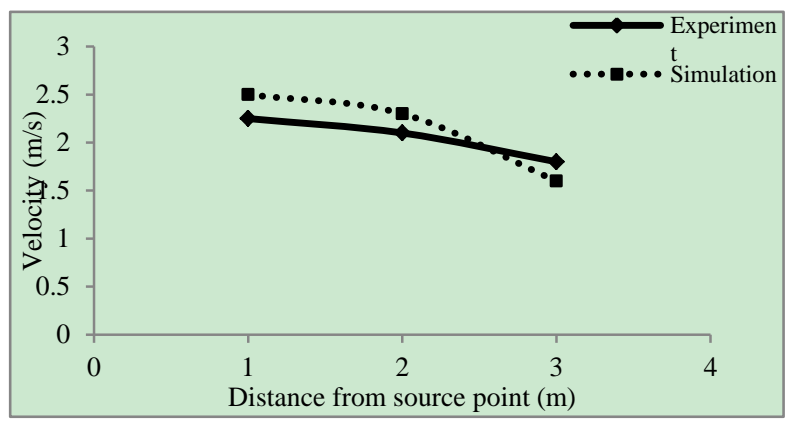

(b) Gas volume flow rate $0.17 \mathrm{Nm}^{3} / \mathrm{s}$

Fig. 4. Center line velocity comparison between experiment and simulation for gas volume flow rates (a) $0.085 \mathrm{Nm} 3 / \mathrm{s}$ and (b) $0.17 \mathrm{Nm} 3 / \mathrm{s}$.

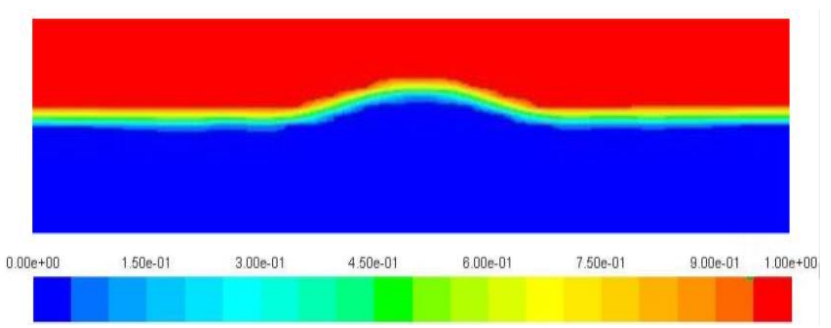

Fig. 5. Contour plot colored by the volume fractions at the water surface.

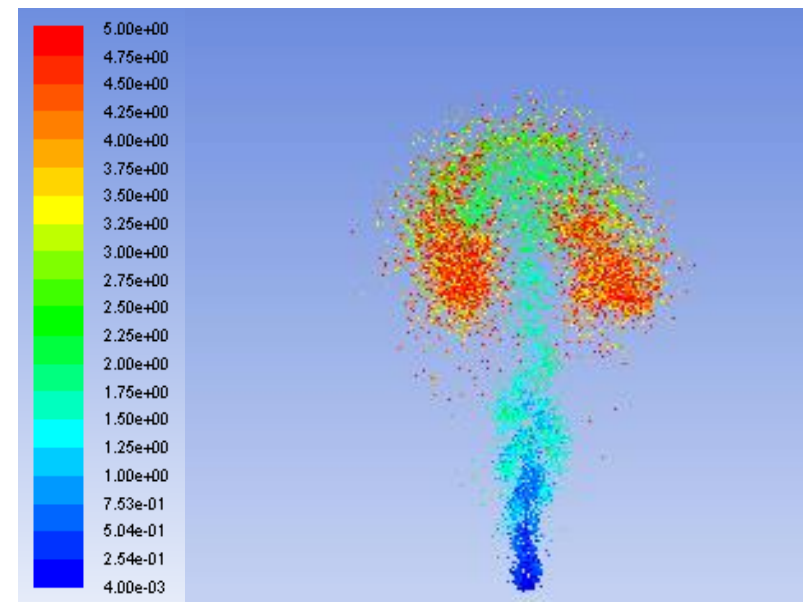

Fig. 6. Shows the bubble contour for particle residance time after 5 seconds at flow rate $0.17 \mathrm{Nm}^{3} / \mathrm{s}$. 


\section{B. Effect of Leakage Hole Size}

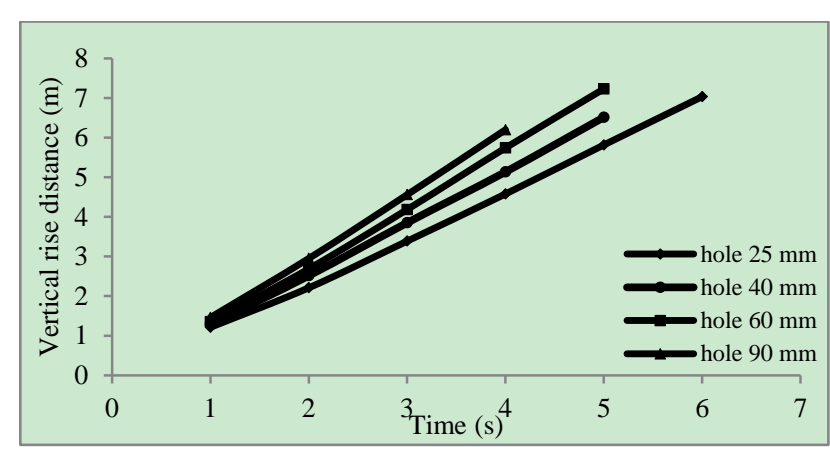

Fig. 7. The vertical rise distance with gas releasing time under various of hole sizes.

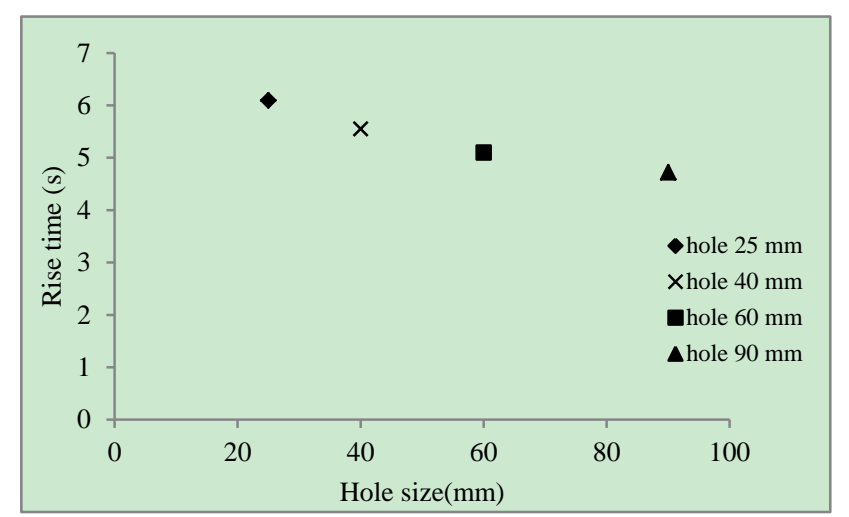

(a) Rise time

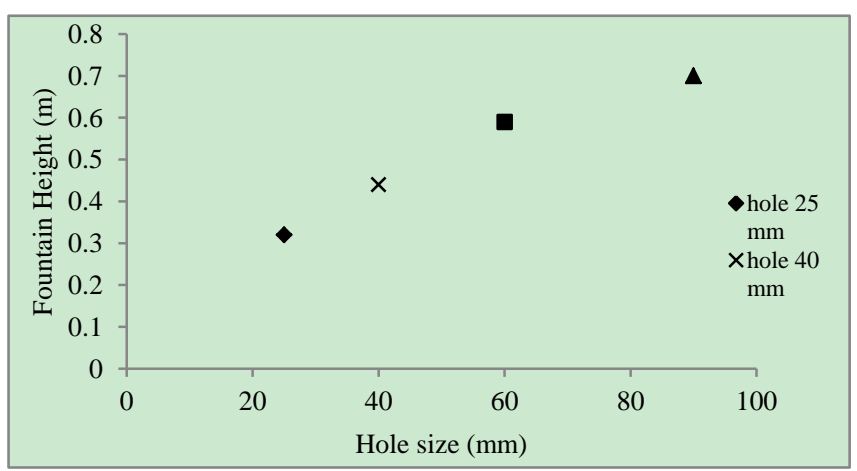

(b) Fountain height.

Fig. 8. Comparison between various scenarios of hole sizes with (a) rise time of gas leakage; (b) fountain height.

The following scenarios with four subsea gas release rates corresponding to variety of hole sizes of $25 \mathrm{~mm}, 40 \mathrm{~mm}, 60$ $\mathrm{mm}, 90 \mathrm{~mm}$ are chosen to evaluate the effect of the gas release rate of the underwater gas dispersion behavior on the same basin of validation model. The initial momentum and buoyancy are the main factors that control the growth of the gas plume, related to the lower gas release rate example, the initial release momentum is lower, therefore, leads to a longer increasing at the rising gas plume time. The comparison of gas plumes factors under various release rates is provided, suggesting that the rate of gas release has a major impact on the gas dispersion. Specifically, at the gas rising time were found that the increasing in a gas release rate leads to decrease in gas rise time. The smaller hole size $25 \mathrm{~mm}$ lead to more rise time $6.093 \mathrm{~s}$ and fountain height $0.32 \mathrm{~m}$ compared with hole size $90 \mathrm{~mm}$ the rise time $4.72 \mathrm{~s}$ and maximum fountain height $0.7 \mathrm{~m}$. The growing trend of vertical rise distance with gas releasing time under various of hole sizes is shown in Fig. 7 and Fig. 9 shows the volume fraction contour for gas flow with water surface. It is apparent that the rate of gas leakage has significantly impacted on the growing gas plume. Therefore, the increase in the gas leakage rate, the lower rise time is expected. As can be concluded comparison between various scenarios of hole sizes with rise time of gas leakage and maximum fountain height.in Fig. 8.
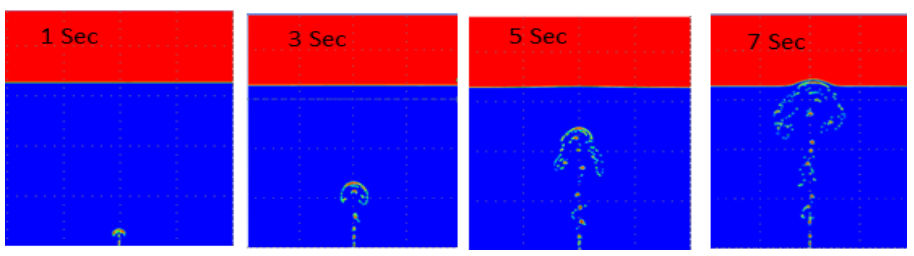

(a) Hole $25 \mathrm{~mm}$
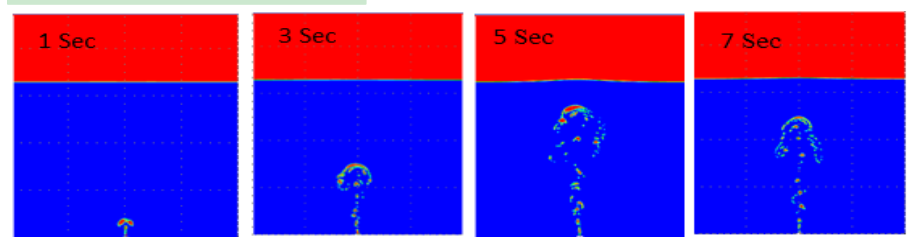

(b) Hole $40 \mathrm{~mm}$
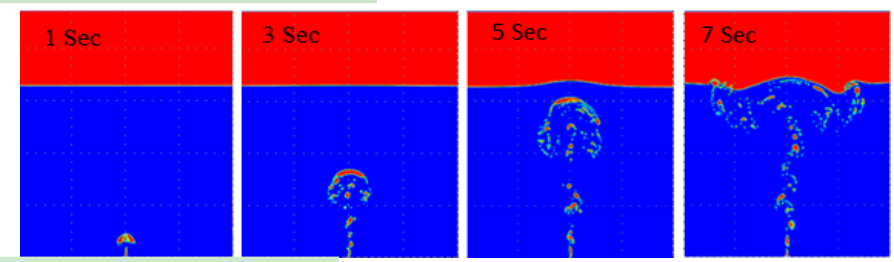

(c) Hole $60 \mathrm{~mm}$
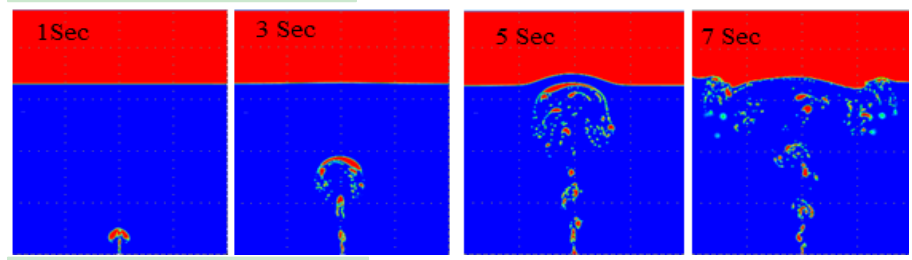

(d) Hole $90 \mathrm{~mm}$

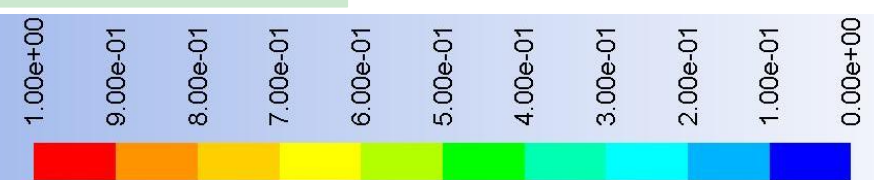

Fig. 9. Volume fraction contour to illustrate the gas flow with water surface at variety of hole sizes (a) hole $25 \mathrm{~mm}$; (b) hole $40 \mathrm{~mm}$; (c) hole $60 \mathrm{~mm}$; (d) hole $90 \mathrm{~mm}$.

\section{Effect of Water Depth}

The depth of water is one of the main factors that impact on the rise time of gas plumes, so it's important to clarify the effect of water depth and it should have a major role in risk assessment. The simulations have conducted by using four different depths as in shallow water ( $4 \mathrm{~m}, 7 \mathrm{~m}, 10 \mathrm{~m}$ and $13 \mathrm{~m}$ ) with gas leakage rate $(2 \mathrm{~m} / \mathrm{s})$. Fig. 10 presents the difference comparison among many parameters that got affected by water depth. Observed that The higher water depth $13 \mathrm{~m}$ lead to more rise time $9.91 \mathrm{~s}$ and fountain height $0.45 \mathrm{~m}$ compared with the smaller water depth $4 \mathrm{~m}$ the rise time $3.24 \mathrm{~s}$ and maximum fountain height $0.55 \mathrm{~m}$. Fig. 11 shows the vertical rise distance with gas releasing time under a variety of water depths, its seem close curves due to the near velocity values in shallow depths. It's clear to say the rise time increases and fountain height decreases with increasing the water depth. Volume fraction contour to illustrate the gas flow with water surface at variety of water depths are concluded in Fig. 12. As 
well notice that the higher water depth contributes to increase the gas plume diameter with considering it is not our topic in this paper.

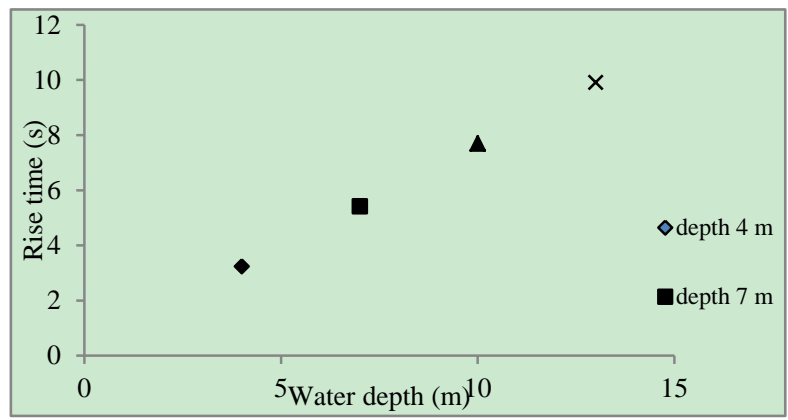

(a) Rise time

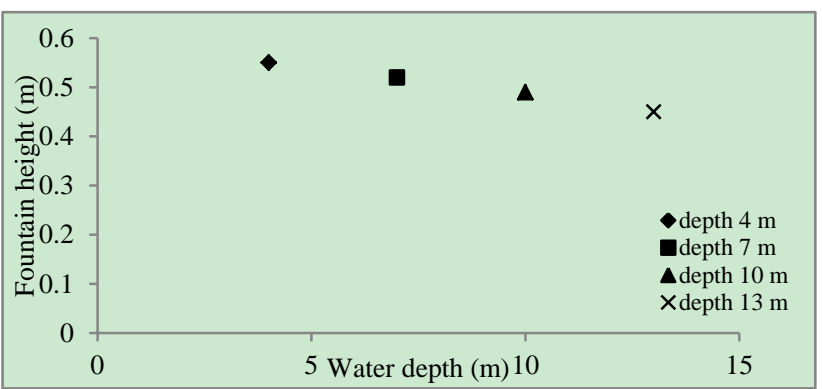

(b) Fountain height.

Fig. 10. Shows the comparison among many parameters that got affected by water depth (a) Rise time; (b) Fountain height.

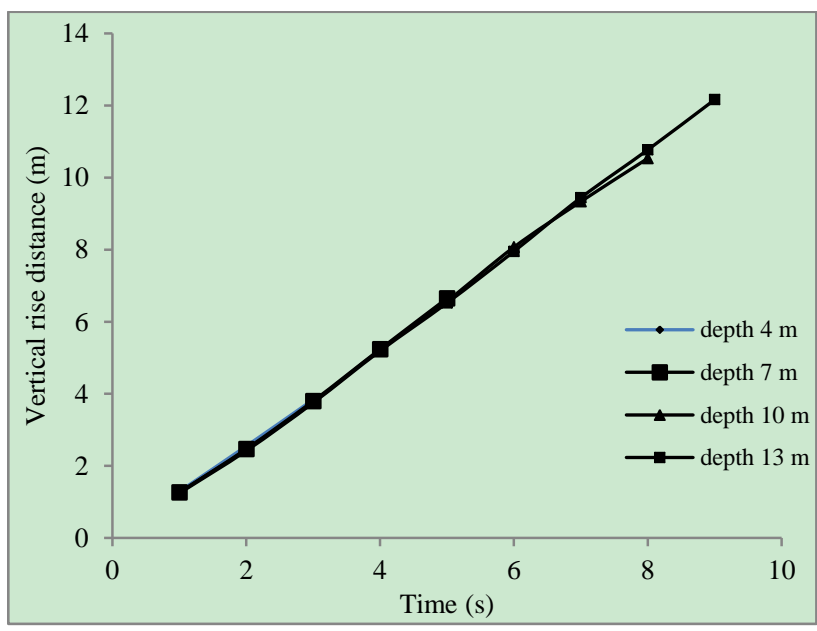

Fig. 11 The vertical rise distance with gas releasing time under a variety of water depths.
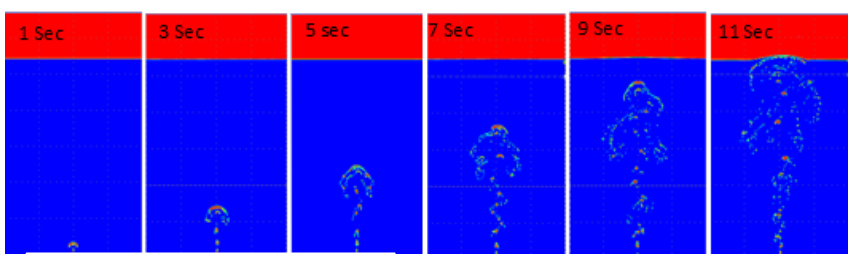

(a) Depth $13 \mathrm{~m}$
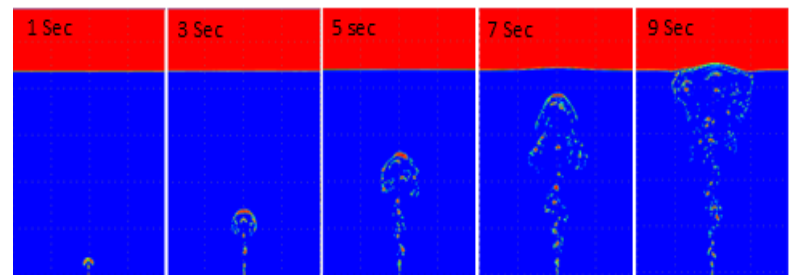

(b) Depth $10 \mathrm{~m}$
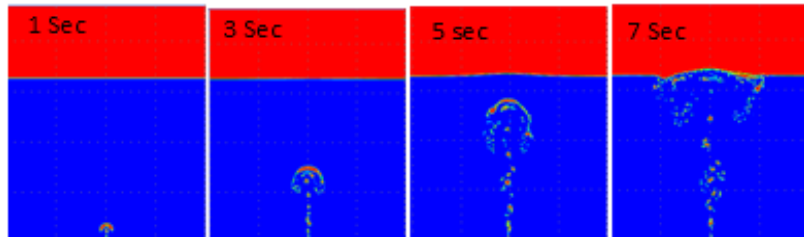

(c) Depth $7 \mathrm{~m}$
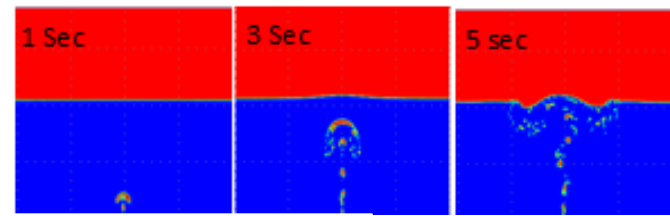

(d) Depth $4 \mathrm{~m}$

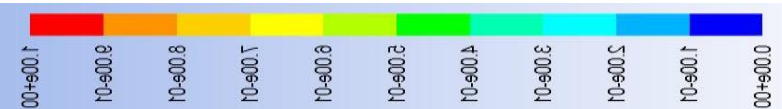

Fig. 12. Volume fraction contour to illustrate the gas flow with water surface at variety of water depths (a) Depth 4 m; (b) Depth 7 m; (c) Depth 10 m; (d) Depth13 m.

\section{CONCLUSION}

A numerical analysis was conducted based on CFD model to study the properties of underwater gas release and to assess the gas dispersion by focus on rising time and fountain height of gas plume in order to mitigate solution for petroleum companies. The main results are summarized in the following

1) The rising time for the hole size $25 \mathrm{~mm}$ is about 1.29 times longer than the scenario of hole size $90 \mathrm{~mm}$. on the other hand the fountain height for larger hole size is approximately 2.1 times higher than the smaller hole size. Therefore, the hole size has a huge impact on the release rate of subsea gas, which increases with the size of the hole.

2) Water depth has a significant role on subsea gas release behaviors, this is obvious from our simulation results that the time needed for the gas plume reached sea surface when the water depth $13 \mathrm{~m}$ is about 3 times longer than the water depth $4 \mathrm{~m}$ whilst the fountain height for lower water depth is near to 1.2 times higher than the deeper water depth.

The scope of this study is modeling of underwater gas release with varying the effected parameters on underwater gas plume. So the future work is planned to build 3D CFD model with considering the effect of ocean current on the underwater gas plume.

\section{REFERENCES}

[1] C. H. Ward et al., Habitats and Biota of the Gulf of Mexico: Before the Deepwater Horizon Oil Spill: Volume 1: Water Quality, Sediments, Sediment Contaminants, Oil and Gas Seeps, Coastal Habitats, Offshore Plankton and Benthos, and Shellfish, Springer New York, pp. 10-22, 2017.

[2] J. A. Pratt and C. J. Castaneda, Offshore Pioneers Brown \& Root and the History of Offshore Oil and Gas, Houston, Texas: Gulf Publishing Company, 1997.

[3] A. Gupta, Modeling and Simulation of Gas Release from Rupture of Subsea Surface Gas Pipe, Indian Institute of Technology, 2014.

[4] L. Zheng and P. D. Yapa, "Modeling gas dissolution in deepwater oil/gas spills," Journal of Marine Systems, vol. 31, pp. 299-309, 2002.

[5] X. Li, G. Chen, H. Zhu, and C. Xu, "Gas dispersion and deflagration above sea from subsea release and its impact on offshore platform," Ocean Engineering, vol. 163, pp. 157-168, 2018.

[6] C. H. Xu et al., "Simulation and assessment of gas dispersion above sea from a subsea release: A CFD-based approach," International Journal 
of Naval Architecture and Ocean Engineering, vol. 11, no. 1, pp. 353-363, 2019

[7] X. Li, G. Chen, and F. Khan, "Analysis of underwater gas release and dispersion behavior to assess subsea safety risk," J Hazard Mater, vol. 367, pp. 676-685, 2019.

[8] Y. Zhang, J. Zhu, Y. Peng, J. Pan, and Y. Li, "Experimental research of flow rate and diffusion behavior of nature gas leakage underwater," Journal of Loss Prevention in the Process Industries, vol.65, 104119, 2020.

[9] S. Cloete, J. E. Olsen, and P. Skjetne, "CFD modeling of plume and free surface behavior resulting from a sub-sea gas release," Applied Ocean Research, vol. 31, no. 3, pp. 220-225, 2009.

[10] F. Jianmin et al., "Simulation and assessment of underwater gas release and dispersion from subsea gas pipelines leak," Process Safety and Environmental Protection, vol. 119, pp. 46-57, 2018.

[11] Y. Sun, X. Cao, F. Liang, and J. Bian, "Investigation on underwater gas leakage and dispersion behaviors based on coupled Eulerian-Lagrangian CFD model," Process Safety and Environmental Protection, vol. 136, pp. 268-279, 2020.

[12] J. E. Olsen and P. Skjetne, "Modelling of underwater bubble plumes and gas dissolution with an Eulerian-Lagrangian CFD model," Applied Ocean Research, vol. 59, pp. 193-200, 2016.

[13] A. S. Kumara and T. Kim, Numerical Comparison of Drag Models Applied to Subsea Gas Dispersion, vol. 1, pp. 259-272, 2018.

[14] X. Li, G. Chen, and H. Zhu, "Modelling and assessment of accidental oil release from damaged subsea pipelines," Mar. Pollut. Bull, vol. 123 , no. 1-2, pp. 133-141, 2017.

[15] J. E. Olsen, P. Skjetne, and S. T. Johansen, "VLES turbulence model for an Eulerian-Lagrangian modeling concept for bubble plumes," Applied Mathematical Modelling, vol. 44, pp. 61-71, 2017.

[16] T. Engebretsen et al., "Surface flow and gas dispersion from a subsea release of natural gas," International Society of Offshore and Polar Engineers, 1997.

Copyright $\odot 2021$ by the authors. This is an open access article distributed under the Creative Commons Attribution License which permits unrestricted use, distribution, and reproduction in any medium, provided the original work is properly cited (CC BY 4.0).

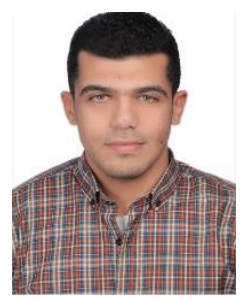

Ahmed M. Ellethy was born in Alexandria, Egypt on 26 July 1992, who graduated from Arab Academy for Science, Technology and Maritime Transport at Egypt in July 2014 with a bachelor's of mechanical engineering (GPA: 3.76, Excellent with honor)

$\mathrm{He}$ is currently working as ROV tooling engineer at Egypt; he has an excellent experience in oil \& gas field which related to subsea networks, operations and structures, especially because he was working previously as a Subsea Controls Engineer on many of control systems such as Vetco Gray, Aker Kvaerner and Cameron in one of Petroleum Companies at Egypt. Therefore, he decided to implement the present study about Subsea gas leakage in order to enhance his experience in oil \& gas field.

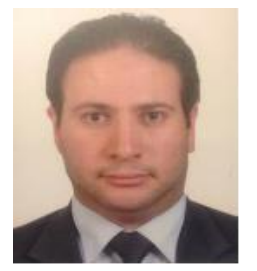

Ahmed S. Shehata was born in Egypt on 25 June 1984, graduated from Arab Academy for Science, Technology and Maritime Transport at Egypt in 2006 with a bachelor's of marine engineering, in 2010 he completed his M.Sc in marine engineering, his thesis title "Aerodynamic Performance of Wells Turbines Wave Energy Extractor" and in 2017 complemented his PhD in Department of Naval Architecture and his thesis title "investigation and improvement of wells turbine performancefluid analysis \& 2nd law of thermodynamics study"

$\mathrm{He}$ is currently working as assistant professor at the Department of Marine Engineering, College of Engineering \&Technology, Arab Academy for Science, Technology and Maritime Transport, Alexandria, Egypt. His current research areas are renewable energy systems, desalination systems, computational fluid dynamics (CFD), structural analysis, offshore structure, oil and gas engineer, process modeling, multi-physics modeling, CAD, and numerical methods.

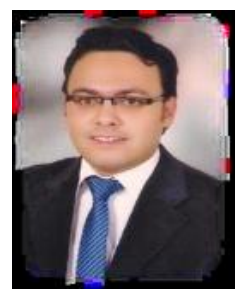

Ali I. Shehata was born in Egypt on 17 December 1981. He was graduated from Arab Academy for Science, Technology and Maritime Transport at Egypt in 2004 with a bachelor's of offshore and marine engineering, in 2007 he completed his M.Sc in Mechanical Engineering, His thesis title "Experimental Investigation of Packed Column Absorption System" and in 2012 complemented his $\mathrm{PhD}$ in the Department of Mechanical Engineering and his thesis title "performance enhancement of vapour absorption cooling systems"

$\mathrm{He}$ is currently working as associate professor at the Department of Mechanical Engineering, College of Engineering and Technology, Arab Academy for Science, Technology and Maritime Transport, Alexandria, Egypt. His current research areas are heat and mass transfer, aircraf applications, aero engines, computational heat transfer, absorption cooling systems, computational fluid dynamics, refrigeration and air conditioning, energy management and renewable energy resources.

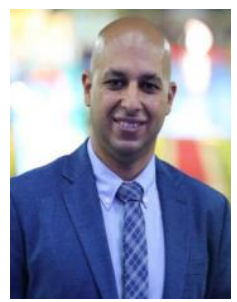

Ahmed Mehanna was born in Egypt on 23 June 1982. He was graduated from Arab Academy for Science, Technology and Maritime Transport at Egypt in 2005 with a bachelor's of marine engineering, in 2009 he completed his M.Sc in marine engineering, his thesis title "Update Development of Design Aspects of Bulk Carriers"." and in 2015 complemented his PhD in Department of Naval Architecture and his thesis title "modeling of oil spill damage assessment in marine environment".

He is currently working as associate professor at the Department of Marine Engineering, College of Engineering \&Technology, Arab Academy for Science, Technology and Maritime Transport, Alexandria, Egypt. His current research areas are marine environment field, ships and offshore structures, risk assessment, marine hydrodynamics, fluid mechanics, ship design, shipbuilding, ship propulsion and renewable energy. 